\title{
In support of creative and useful science
}

\author{
EVERT GUMMESSON
}

Evaluating scientific work is no easy task. Those who claim they can provide a strict system are misled.

They can't; science as a reflection of 'reality' and 'truth' is too complex and varied. However, their advocacy is currently spreading like wildfire to journals, examiners, universities, grants committees and others. By denying the complexity and variety of science, a community of academic and political power-centers is reducing science to a bureaucratic and political system, a planned economy. No doubt guidelines and criteria can provide useful checklists for assessing journal articles but they are not sufficient as they only cater for certain aspects. Here are ten comments and objections.

1. We are victims of systems. I realize the necessity of getting ranked; that's the way the system currently works. But I am deeply concerned about the direction in which the ranking and 'quality' measurements go. They are more quantity indicators assumed to be a proxy for quality, hidden behind anonymous reviewers with their idiosyncrasies, arbitrary 'quality' criteria, trendy politics and overly detailed metrics. The truth is a number and a decimal (or two or three ...) even if it is subjectively founded and only shows probabilities. These metrics lure and force young researchers into a behavior that does not support development for the future. We have a global financial crisis that seems deeper and longer than ever before. How does the ranking system give incentives to scholars to help us out of the crisis?

2. Ritual over relevance. A journal should not be allowed to claim it's a top journal unless it supports pluralism, many ways of approaching a problem and many ways of selecting and defining it. Marketing Theory does so, and I hope it will in the future, too. Many 'top' journals are narrow and promote subjectively determined methodological rituals under the pretense of being rigorous and objective. In fact they are obsessively and subjectively stuck on technicalities.

" This is a slightly revised version of a contribution by Gummesson Evert, "In support of creative and useful science", originally published in Firat, Fuat A., ed. (2010), "Commentaries of the state of journals in marketing", Marketing Theory, vol. 10, n. 14, pp. 438-441. Reprinted by permission.

** Professor of Service Management and Marketing at Stockholm University

e- mail: eg@fek.su.se 
And yet they publish articles which do not even fulfil their own aggressively promoted 'scientific' criteria, as one article in Marketing Theory clearly showed: Collier, J.E. and Bienstock, C.C. (2007) 'An Analysis of how Nonresponse Error is Assessed in Academic Marketing Research', 7(2): 163-83. It is also rich in data on other dimensions than nonresponses and presents the data for five years for $J M, J M R$ and $J A M S$. It is not flattering. If you have not read it, do so.

3. Technique over relevance: 'survey-dominant logic'. Top journals keep publishing statistical surveys on very limited subjects and with little or no possibility to generalize and add to marketing knowledge. The survey technique is in itself shallow and used more for researcher convenience (for example a sample of 'students on campus'!!!) and quick and safe publishing than for developing marketing understanding. I am constantly approached by $\mathrm{PhD}$ students around the world who say: 'I can't publish without doing a quantitative study. But I find it irrelevant'. Marketing Theory could perhaps even more actively help change this perception.

4. More-of-the-same over development and innovation. Articles on theoretical development are judged harder than the mainstream repetition of what we already know. There is a lack of theory generation in marketing both on a midrange and a grand level. Marketing Theory has been open here and I hope will continue to be so.

5. Name dropping over important references. Most of what is published is wasted except as a career step for the authors. To reach out with important developments and be picked up by others is now limited to ritual: search 'top' journals and the celebs of the field and trust the anonymous search engine programmers to be objective and wise. Some of these references are undoubtedly good, sometimes (but not often) excellent; but unknown journals and unknown authors can be equally good, even better. So the system does not support accumulation of knowledge, new paradigms and other developments. Worse still, the system feels snug and does not even try to handle the huge amount of knowledge development that is going on but can't make itself visible. And everything is limited to the English language and US values. US professors and journals are good at selling. I do not blame them for that. I rather blame the academic 'buyers' around the world and their insecurity, lack of courage and lack of scholarly integrity. Assessing scholarly contributions is risky and complex. It cannot be hidden behind quantitative measures of the brands of journals, the celebrity status of authors, and bibliometrics.

6. The established over entrepreneurship. $J M$ is 77 years old, Marketing Theory is 13, and other journals are being started today. A new journal may be started because a new field is in the making. I have experienced some of it: services marketing started to gain a critical mass of researchers in the 1970s, followed by relationship marketing, networks and currently a breakthrough for servicedominant logic and service science. The latter two are essentially syntheses and reconceptualization of extant knowledge, the scrapping of irrelevant mainstream claims and adaptation to contemporary marketing contexts. Complexity and 
context, shunned in the 'survey-dominant logic' and 4P approach, are appearing on the agenda through network theory, systems thinking and ongoing/in depth cases. Publishing in a new journal addressing an important new area does not give any formal credit to the authors.

7. International - read: English-speaking journals, read: US journals. 'International' article publications have become the No. 1 criterion for academic promotion and this is supported by the US, governments, the EU and others. Books don't count and reports with limited circulation don't count. Who created this monstrous strategy? Dr Frankenstein? Other languages, even if spoken by tens or hundreds of millions of people, don't count. We need pluralism and scholars (by which I mean architects, not technicians like plumbers). We do not need uniform tin soldiers. Note that the criteria used today are subjectively or intersubjectively based, they often lack common sense and reflection and they lack objectivity. The European Marketing Academy (EMAC), which should support pluralism in Europe and its 35 or so languages and numerous business cultures, has succumbed to US 'values' and, through its journal, promotes these values. The EMAC journal should not be a clone of US journals. It should be a role model for European journals and a challenge and competitor to US journals. As marketers we believe in competition as a driving force of development, don't we? But now 'scientific' publishing in social sciences is becoming a centrally planned economy.

8. Historical testing over continuous improvements. The best way to test an established 'truth', a concept, theory and so on, is to offer a better alternative. Hypothesis testing of old results and concepts is retrospective and engages brain capacity in non-productive work. Instead, continuous theory development should be in focus and be stimulated. Theory testing and theory generation are not enemies. They should walk hand in hand; they are not two different species of science.

9. Bureaucracy over entrepreneurship. The majority of academic faculty (not to talk about university administrators and politicians, both essentially ignorant of how knowledge and understanding is spawned) is conservative and bureaucratic, they are not innovators and entrepreneurs. They are workers at the assembly line of educational factories. There is no balance today between 'law and order' (which is needed to some extent but is not the mission of science) and 'breaking new ground' (which is the mission of science). Science is risky as it is detecting the yet unknown and the future. The belief that this process can be organized through a rigid 'quality' system is a sign of ignorance.

10. Words of consolation. Fighting the system is a risky task, but systems, like epidemics, reach a sudden tipping point and can even fall overnight like the Berlin Wall. We may feel that we have to comply with systems out of fear for our careers and mortgage payments and peer disapproval. We should, however, be aware of systems' shortcomings - more so as scholars than any other professional group. We should try to improve systems or replace them. Even if unfortunate and powerful systems can be sustained for some time and harm one 
or several generations, academics have shown inventiveness in dodging systems and fooling the power elite.

These were some of my concerns and I am sure not everybody agrees. I don't mind; show me a better way of thinking and I will be happy to 'steal' it from you. I would very much like Marketing Theory to be a role model for publishing sound and useful research based on content and relevance and not on appearances and political fads. 